\title{
Placenta accreta spectrum: risk factors and fetomaternal outcome after multidisciplinary team approach
}

\author{
Kanchan Rani, Shubhra Srivastava \\ Corresponding author: Dr. Kanchan Rani, Associate Professor, Department of Obstetrics and \\ Gynaecology, Teerthankar Mahaveer Medical College, Moradabad, Uttar Pradesh, India; \\ Email : drkanchanrani@gmail.com
}

Distributed under Attribution-Non Commercial - Share Alike 4.0 International (CC BY-NC-SA 4.0)

\begin{abstract}
Background: Placenta accreta spectrum (PAS) is an entity where abnormal trophoblastic invasion of placenta occurs into myometrium of uterine wall either partially or totally. Maternal and perinatal morbidity and mortality is increased in PAS due to severe hemorrhage, requirement of blood transfusion and need for peripartum hysterectomy. Objective: To find out risk factors and fetomaternal outcome after multidisciplinary team approach in cases of placenta accreta spectrum. Material and methods: All case records were obtained from medical record section and carefully analyzed to find out risk factors and primary and secondary outcome measures. Results: Maximum patients were in age group of 30-34 years $(48.83 \%)$ and were third gravida (39.53\%). $34.88 \%$ cases had history of previous 2 LSCS (lower segment caesarian section) and in $67.44 \%$ it was associated with placenta previa. 67.44\% had postpartum haemorrhage (PPH) with $48.83 \%$ unbooked cases. $41.18 \%$ cases went into hemorrhagic shock with $34.38 \%$ falling into unbooked category. $69.76 \%$ had intensive care unit (ICU) admission due to various indications out of which $83.33 \%$ were unbooked and $16.67 \%$ were booked. $69.44 \%$ baby of unregistered pregnancy went to neonatal intensive care unit (NICU) in comparison to $30.56 \%$ of registered cases. Conclusion: Placenta accreta spectrum is associated with adverse maternal and perinatal outcome. Prenatal diagnosis and multidisciplinary team management can improve prognosis of both fetal and maternal outcome.
\end{abstract}

Keywords: Placenta accreta, postpartum hemorrhage, conservative treatment, peripartum, hysterectomy.

Placenta accreta spectrum is defined as either an entity where there is abnormal trophoblastic invasion of placenta into myometrium of uterine wall partially or totally ${ }^{1}$. Incidence of placenta accreta spectrum is 1.7 per 10000 deliveries. The incidence is more in women with previous caesarean deliveries and placenta previa i.e. 577 per 10000 deliveries. $^{2}$ The pathogenesis is related to the defective decidulisation of the implantation site and there is absence of both the decidua basalis and the nitabuch's layer which results in a direct attachment of the chorionic villi to the myometrium. ${ }^{3,4}$

Placenta accreta spectrum is an increasingly common and potentially dangerous obstetric entity as the rate of caesarean delivery has increased substantially over past few decade so has the incidence complicated by placenta accreta spectrum disorder. ${ }^{5,6}$ Placenta accreta spectrum previously known as morbidly adherent placenta has 3 subtypes depending on depth of invasion of trophoblast: 1. Accreta - placental villi are attached to the myometrium 2. Increta - Invasion of placental villi into the myometrium 3. Percreta - Placental villi fully penetrate into the myometrium. It includes cases where placental villi breaches the serosa and surrounding structures bladder, broad ligament or bowel. ${ }^{2}$ Incidence of placenta accreta are more common than placenta increta and percreta.

There are numerous risk factors, which are shown to be

Received: $2^{\text {nd }}$ July 2020, Peer review completed: $14^{\text {th }}$ August 2020, Accepted: $7^{\text {th }}$ September 2020.

Rani K, Srivastava S. Placenta accreta spectrum: risk factors and fetomaternal outcome after multidisciplinary team approach. The New Indian Journal of OBGYN. 2021; 8(1): 112-16. 
The New Indian Journal of OBGYN. 2021 (July-December);8(1)

associated with placenta accreta. These factors include placenta previa prior uterine surgery increased parity, thin decidua and advanced maternal age. However, the risk increases with increasing number of previous caesarean section. There is twofold increase in risk in patients with prior caesarean section and eightfold increase in risk in women with two or more prior caesarean section. ${ }^{3}$

The majority of placenta accreta occurs in multiparous women especially in those with at least one caesarean delivery. As the number of prior caesarean increases so does risk of encountering placenta accreta, increta or percreta. ${ }^{5}$ Ultrasonographic findings suggestive of placenta accreta are as follows: presence of multiple placental lacunae (sensitivity - 93\%); interruption of posterior bladder wall uterine interface (sensitivity-20\%, specificity-100\%); obliteration of the clear space between the uterus and placenta (sensitivity-80\%); hyper vascularity of adjacent bladder wall and myometrium thickness less than $1 \mathrm{~mm}$, turbulent lacunar blood flow on color doppler imaging ${ }^{6,7}$. But absence of ultrasonographic findings does not preclude a diagnosis of PAS and clinical risk factors should be considered equally important predictors for PAS. ${ }^{8}$

Maternal morbidity and mortality is increased in PAS due to severe hemorrhage, requirement of blood transfusion and need for peripartum hysterectomy. ${ }^{8}$ So, we conducted a study to critically analyze all risk factors for placenta accreta spectrum their management and maternal and fetal outcome after team managed care.

\section{Material and methods}

This is a retrospective study conducted for a period of three years from February 2017 to February 2020. All cases of placenta accreta spectrum delivered in the department of obstetrics and gynecology at Teerthankar Mahaveer medical college, Moradabad during study period were included in the study. All case records were obtained from medical record section and carefully analyzed to find out primary and secondary outcome measures: risk factors (maternal age, parity, prior caesarean section, previous dilatation and evacuation), and clinical presentation and maternal and perinatal morbidity and mortality in unbooked cases and in those cases who were given multidisciplinary care.

Data were recorded in excel sheet and all calculations were done using SPSS (Statistical Package for the Social Science; SPSS Inc. ver. 21). Categorical variables were summarized through the calculation of frequency and percentage when appropriate relative frequency. Data of continuous variables were described as mean and standard deviation (SD). The 95\% confidence intervals and 2-tailed "P" values were calculated. A "P" value of $<0.05$ was considered to be statistically significant.

\section{Results}

Out of total number of reported 86 cases, maximum patients $(48.83 \%)$ were in age group of $30-34$ years followed by 25-29 years of age $(25.58 \%)$. Maximum patients were third gravida $(39.53 \%)$. Only $2.32 \%$ of patients with PAS were primigravida (table 1 ). We had $44.18 \%$ booked cases and $55.82 \%$ were unbooked patients (table 2 ).

Table 1: Demographic profile of patients

\begin{tabular}{llll}
\hline Parameters & & $\begin{array}{l}\text { No. of patients } \\
\text { (n-86) }\end{array}$ & $\begin{array}{l}\text { Percentage } \\
\text { (\%) }\end{array}$ \\
\hline Age groups & $20-24$ & 10 & 11.62 \\
(years) & $25-29$ & 22 & 25.58 \\
& $30-34$ & 42 & 48.83 \\
& $35-39$ & 12 & 13.95 \\
& $>39$ & 0 & 0 \\
\hline Parity & Primi & 2 & 2.32 \\
& Gravida 2 & 26 & 30.23 \\
& Gravida 3 & 34 & 39.53 \\
& $>3$ & 24 & 27.90
\end{tabular}

Table 2: Booking status of patients

\begin{tabular}{lll}
\hline Categories & No. of patients & Percentage (\%) \\
\hline Booked & 38 & 44.18 \\
Unbooked & 48 & 55.82 \\
Total & 86 & 100 \\
\hline
\end{tabular}

$34.88 \%$ cases had history of previous 2 lower segment caesarian section (LSCS) and in $67.44 \%$ cases it was associated with placenta previa with previous LSCS. In $27.9 \%$ cases patient had history of dilatation and evacuation (D\&E) (table 3).

Table 3: Obstetric risk factors of patients

\begin{tabular}{lll}
\hline Obstetric risk factors & No. of patients (percentage) & P-value \\
\hline Previous 1 LSCS & $26(30.23)$ & $<0.05$ \\
Previous 2 LSCS & $30(34.88)$ & $<0.05$ \\
$\geq 3$ LSCS & $14(16.27)$ & $<0.05$ \\
Previous D\&E & $24(27.90)$ & $<0.05$ \\
Placenta previa with & & \\
previous LSCS & $58(67.44)$ & $<0.05$ \\
Previous uterine surgery & $2(2.32)$ & $<0.05$ \\
\hline
\end{tabular}

LSCS - Lower segment caesarian section; D\&E - Dilatation and evacuation

PAS was diagnosed by ultrasonography (USG) in $68.66 \%$ cases while in $31.14 \%$ cases ultrasound findings were not able to diagnose PAS. Even in $8.14 \%$ registered cases USG was not showing features of placenta accrete and patient was clinically suspected as a case of placenta accreta (table 4 and 5). $65.12 \%$ presented as antepartum hemorrhage, $1.16 \%$ of unbooked cases came as postpartum haemorrhage $(\mathrm{PPH})$ and $1.16 \%$ presented as retained placenta (table 6). $67.44 \%$ had $\mathrm{PPH}$ out of which $72.41 \%$ were unregistered with $\mathrm{p}$ value $<0.05$, total $41.86 \%$ of patients of hemorrhagic shock, $83.33 \%$ were unbooked. $69.76 \%$ had intensive care 
The New Indian Journal of OBGYN. 2021 (July-December);8(1)

unit (ICU) admission with $83.33 \%$ unbooked cases with $\mathrm{p}$ value $<0.05$.

\begin{tabular}{lcl}
\multicolumn{2}{l}{ Table 4: Diagnosis of PAS in study patients } & \\
\hline Diagnosis of patients & $\begin{array}{l}\text { No. of } \\
\text { patients }\end{array}$ & $\begin{array}{l}\text { Percentage } \\
(\%)\end{array}$ \\
\hline $\begin{array}{l}\text { Booked case diagnosed as a case of } \\
\text { PAS by USG }\end{array}$ & 31 & 36.05 \\
$\begin{array}{l}\text { Booked case clinically suspected as } \\
\text { PAS but not diagnosed by USG }\end{array}$ & 7 & 8.14 \\
$\begin{array}{l}\text { Unbooked cases diagnosed } \\
\text { PAS by USG }\end{array}$ & 28 & 32.56 \\
$\begin{array}{l}\text { Unbooked cases diagnosed PAS } \\
\text { preoperative / during surgery } \\
\text { Total }\end{array}$ & 20 & 23.26 \\
\hline PAS - Placenta accreta syndrome; USG - Ultrasonography \\
\hline
\end{tabular}

\begin{tabular}{lll}
\multicolumn{3}{l}{ Table 5: Ultrasonography in diagnosis of PAS } \\
\hline Categories & No. of patients & Percentage (\%) \\
\hline Diagnosis by USG & 59 & 68.6 \\
Not diagnosed by USG & 27 & 31.4 \\
Total & 86 & 100 \\
\hline
\end{tabular}

Table 6: Presenting complaints

\begin{tabular}{llll}
\multicolumn{2}{l}{ Table 6: Presenting complaints } \\
\hline Categories & \multicolumn{2}{l}{ Number of patients } & \multirow{2}{*}{ Total } \\
\cline { 2 - 3 } & Booked & Unbooked & \\
\hline Antepartum hemorrhage & $10(11.63 \%)$ & $46(53.49 \%)$ & $56(65.12 \%)$ \\
Postpartum hemorrhage & 0 & $1(1.16 \%)$ & $1(1.16 \%)$ \\
Retained placenta & 0 & $1(1.16 \%)$ & $1(1.16 \%)$ \\
\hline
\end{tabular}

Table 7: Maternal outcome of patients

\begin{tabular}{llllll}
\hline $\begin{array}{l}\text { Maternal } \\
\text { outcomes }\end{array}$ & $\begin{array}{l}\text { No. of patients } \\
\text { (Percentage) }\end{array}$ & Booked & Unbooked & 95\% CI & P - value \\
\hline PPH & $58(67.44 \%)$ & $16(27.5 \%)$ & $42(72.41 \%)$ & $26.97-58.73$ & $<0.05$ \\
Hemorrhagic shock & $36(41.86 \%)$ & $6(16.67 \%)$ & $30(83.33 \%)$ & $43.72-79.48$ & $<0.05$ \\
DIC & $2(2.33 \%)$ & 0 & $2(100 \%)$ & $7-100$ & $>0.05$ \\
Bladder injury & $2(2.33 \%)$ & 0 & $2(100 \%)$ & $7-100$ & $>0.05$ \\
Sepsis & $8(9.5 \%)$ & $1(12.5 \%)$ & $7(87.5 \%)$ & $27.35-40.11$ & $>0.05$ \\
ICU admission & $60(69.76 \%)$ & $10(16.67 \%)$ & $50(83.33 \%)$ & $50.59-77.06$ & $<0.05$ \\
Death & $2(2.33 \%)$ & 0 & $2(100 \%)$ & $7-100$ & $<0.05$ \\
\hline
\end{tabular}

PPH - Post partum hemorrhage; DIC - Disseminated intravascular coagulation; ICU - Intensive care unit; CI- Confidence interval; P-value $<0.05$ - Significant

\begin{tabular}{lllll} 
Table 8: Management of patients & & & \\
\hline Management & $\begin{array}{l}\text { Booked } \\
\text { patients }\end{array}$ & $\begin{array}{l}\text { Unbooked } \\
\text { patients }\end{array}$ & Total & Percentage \\
\hline Hysterectomy & $30(34.88 \%)$ & $36(41.86 \%)$ & 66 & 76.74 \\
Expectant management & $2(2.33 \%)$ & 0 & 2 & 2.33 \\
Conservative surgery & $6(6.98 \%)$ & $12(13.95 \%)$ & 18 & 20.93 \\
\hline
\end{tabular}
belong to age group 30 to 34 years and $55.82 \%$ of them were unbooked cases. In a similar study by Dwivedi et al in 2016, 45.95\% belonged between 35 to 40 years of age. So there was increase in risk of placenta accreta spectrum with increasing age.

\begin{tabular}{llllll}
\hline \multicolumn{2}{l}{ Table 9: Neonatal outcome } & & & \\
\hline Neonatal outcome & $\begin{array}{l}\text { Total no. of } \\
\text { patients }\end{array}$ & $\begin{array}{l}\text { Booked } \\
\text { patient }\end{array}$ & $\begin{array}{l}\text { Unbooked } \\
\text { patient }\end{array}$ & $\mathbf{9 5 \%}$ CI & P-value \\
\hline NICU admission & $36(41.86 \%)$ & $11(30.56 \%)$ & $25(69.44 \%)$ & $15.83-56.63$ & $<0.05$ \\
LBW & $38(44.19 \%)$ & $20(52.63 \%)$ & $18(47.37 \%)$ & $30.7-2100$ & $>0.05$ \\
IUD & $4(4.65 \%)$ & 0 & $4(100 \%)$ & $30.72-100$ & $<0.05$ \\
\hline NICU - Neonatal intensive care unit; LBW - Low birth weight; IUD - Intrauterine death & \\
\hline
\end{tabular}

Advanced maternal age is also reported independent risk factors for accreta with the risk increasing for every year beyond 20 years of age. ${ }^{9}$ In a similar study by

$76.74 \%$ patient was managed by hysterectomy, $2.33 \%$ had expectant management and $20.93 \%$ had conservative surgery (table 8). 41.86\% newborn had neonatal intensive care unit (NICU) admission out of which $30.56 \%$ were booked and $69.44 \%$ booked cases with $\mathrm{p}$ value $<0.05$. $44.19 \%$ were low
Ferquor et al the median age of women with placenta accreta was 35 years. ${ }^{10}$ In our study $39.53 \%$ patients were gravida 3 and only $2.32 \%$ patients were primigravida. According to Dwivedi et al $95 \%$ patients were multigravida and only $5 \%$ were primigravida. ${ }^{9}$ 
We found placenta previa with previous LSCS as major risk factor present in $67.44 \%$ of cases (previous 1 LSCS $30.23 \%$, previous 2 LSCS $-34.88 \%$, previous 3 or more LSCS $-16.27 \%$ ) followed by history of D\&E $-27.9 \%$. In a similar study by Dwivedi S et al, $67 \%$ had previous 1 LSCS, $19 \%$ had previous 2 LSCS, $83 \%$ had placenta previa and $29 \%$ were with history of D\&E. ${ }^{9}$

A large multicentric US cohort study had also reported that for women with placenta previa and prior caesarean deliveries the risk of accreta was $3 \%, 11 \%, 40 \%, 61 \%$ and $67 \%$ for first, second, third fourth and fifth or more caesarean respectively ${ }^{11}$. Also a report from national institute of health ${ }^{12}$ states that $0.3 \%, 0.6 \%$, and $2.4 \%$ of those having had one, two and three previous caesarean births respectively will develop placenta accreta in subsequent pregnancies.

In our study $36.05 \%$ were diagnosed as case of PAS by USG while in $8.14 \%$ booked cases USG could not diagnose PAS. They were suspected to be a case of placenta accreta due to high risk factors and were managed as PAS $\quad 23.26$ $\%$ unbooked cases were not diagnosed as placenta accreta on USG and they were diagnosed preoperatively or during delivery. So in total $68.6 \%$ were diagnosed by USG while in $31.4 \%$ cases USG alone was not able to predict PAS. In another study $48 \%$ of PAS were diagnosed by ultrasound ${ }^{13}$.

According to a study by Adel EL Wakeel, sensitivity and specificity of USG were $63.6 \%$ and $91.6 \%$ respectively. ${ }^{14}$ So USG may not able to diagnose all cases of PAS. Clinical risk factors should also be considered along with USG for the diagnosis.

$65.12 \%$ presented as antepartum hemorrhage of which $53.49 \%$ were unbooked and only $11.63 \%$ booked cases presented as antepartum haemorrhage (APH) in our study. In a similar study $48 \%$ patient presented as $\mathrm{APH}^{9}$.

In our study $67.44 \%$ cases had some amount of PPH out of which $27.59 \%$ were booked and $72.41 \%$ were unbooked. $41.86 \%$ underwent hemorrhagic shock out of which $16.67 \%$ were booked cases and $83.33 \%$ were unbooked. $\mathrm{P}$ value of both $\mathrm{PPH}$ and hemorrhagic shock was less than 0.05 showing it was significantly high in unbooked cases.

In our study 2 cases had disseminated intravascular coagulation (DIC) and 2 cases had bladder injury which was repaired and both were unbooked. $69.76 \%$ had ICU admission due to various indications, out of which $83.33 \%$ were unbooked and $16.67 \%$ were booked with $\mathrm{P}$ value less than 0.05 showing significant association with ICU admission in unbooked cases. There were 2 maternal deaths in unbooked cases due to hemorrhagic shock with DIC because they were already in critical condition with APH and shock at the time of admission in the institute. In a study by Dwivedi $\mathrm{S}$ et al $86 \%$ women had $\mathrm{PPH}$ and $43 \%$ went into hemorrhagic shock, $16 \%$ suffered bladder injury, $2 \%$ developed DIC and there were $18 \%$ maternal deaths. ${ }^{14,9}$ $76.74 \%$ women in our study were managed by hysterectomy. Among these $41.86 \%$ were unbooked. $2.33 \%$ had expectant management and $20.93 \%$ had conservative surgery. In a study by Dwivedi S et al hysterectomy was done in $78 \%{ }^{9}$

30 women of 38 booked cases were managed by primary hysterectomy after delivery of baby. 2 patients had expectant management where placenta was left in situ with follow up. Conservative surgery was done in 6 of 38 booked cases with systematic devascularisation or oversewing of placental bed in order to preserve future fertility. All cases of conservative surgery were placenta accreta with focal invasion. Out of 48 unbooked cases 12 were managed by conservative surgery as they were diagnosed as PAS during caesarean section when placenta was not removed completely after delivery of baby. They were cases of focal invasion of placenta where some parts of placenta were left with varied amount of bleeding. In 36 unregistered cases, primary hysterectomy was done after delivery of baby. In a similar study $78 \%$ patient had hysterectomy, $17 \%$ had placental retention and $5 \%$ of patient had methotrexate ${ }^{9}$.

$69.44 \%$ of baby of unbooked pregnancy went to NICU in comparison to $30.56 \%$ of booked cases with $p$ value less than 0.05 showing significant number of NICU admission in unbooked cases. But a study by Abdulla et al showed no difference in neonates admitted to NICU between both the groups. $^{15}$

Low birth weight in booked cases were 52.63\% and $47.37 \%$ in unbooked with $\mathrm{P}$ value more than 0.05 . So there was not much difference in low birth weight in both groups. There were 4 IUDs $(4.65 \%)$ in unbooked cases. Fetal outcome was good in registered cases in spite of not much difference in low birth weight in both the groups in our study.

\section{Conclusion}

Placenta accreta spectrum appears to be associated with adverse maternal and fetal outcome some of which may be life threatening. Antenatal diagnosis should be made not only on ultrasound findings but suspected on presence of high risk factors also. Adequate delivery planning at a tertiary care center with help of multidisciplinary team improves both maternal and fetal outcome in terms of morbidity and mortality. 
Conflict of interest: None. Disclaimer: Nil.

\section{References}

1. Bray F, Ferlay J, Soerjomataram I, Siegel R, Torre L, Jemal A. Global cancer statistics 2018: GLOBOCAN estimates of incidence and mortality worldwide for 36 cancers in 185 countries. CA: A Cancer Journal for Clinicians. 2018; 68(6): 394-424.

2. Karya U, Zehra A, Rani A. Evaluation of Swede score and Reid score to improve the predictive value of colposcopy and its correlation with histology. International Journal of Reproduction, Contraception, Obstetrics and Gynecology. 2020; 9(5): 2059-67.
Swati Priya ${ }^{1}$, Raghunandan Kumar ${ }^{2}$, Gauri Gandhi ${ }^{3}$, Suhagini Murmu ${ }^{4}$, Krishana Agarwal ${ }^{5}$

${ }^{1}$ Senior Resident, Department of Obstetrics and Gynecology, AlIMS, Patna, Bihar, India; ${ }^{2}$ Senior Resident, Department of Anesthesia, JNKTMCH, Madhepura, Bihar, India; ${ }^{3}$ Director-Professor, Department of Obstetrics and Gynecology, Maulana Azad Medical College and associated hospital, New Delhi, India; ${ }^{4}$ Senior Resident, Department of Obstetrics and Gynecology, AlIMS, Patna, Bihar, India; ${ }^{5}$ Associate Professor, Department of Obstetrics and Gynecology, Maulana Azad Medical College, New Delhi, India. 